\title{
TRANSFER MATRIX COMPUTATION FOR WAVE ACTION SIMULATION IN AN INTERNAL COMBUSTION ENGINE
}

\author{
Haitham MEZHER ${ }^{1}$, David CHALET and Pascal CHESSÉ \\ LUNAM Université, École Centrale de Nantes, LMF UMR CNRS 6598 \\ 1, rue de la Noë, BP 92101, 44321 Nantes Cedex 3, France \\ ${ }^{1}$ Contact Author \\ Jérôme MIGAUD and Vincent RAIMBAULT \\ Advanced Development, Mann+Hummel \\ Laval, France
}

\section{ABSTRACT}

A new technique for simulating engine pressure waves consisting of linking pressure response and mass flow rate excitation in the frequency domain has been presented. This is achieved on the so-called "dynamic flow bench". With this new approach, precise, fast and robust results can be obtained while taking into account all the phenomena inherent to compressible unsteady flows. The method exhibited promising results when it was incorporated in a GT-Power/Simulink coupled simulation of a naturally aspirated engine.

However, today's downsized turbocharged engines come with more stringent simulation necessities, where discontinuities such as the charge air cooler (CAC) must be correctly modeled. Simulating such engines with the transfer function methodology is quite difficult because it requires mounting the entire intake line on the bench. Modeling wave action for these engines requires an understanding in the frequency domain of the flow's characteristics through the different elements that make up the intake line. This leads us to study the acoustic transfer matrices.

In order to split the intake line into separate elements, a straight duct of $185 \mathrm{~mm}$ length is chosen as a first reference. It is mounted on the dynamic flow bench and pressure response is measured after an impulse mass flow excitation. Transfer functions of relative pressure and mass flow rate are then identified at given points upstream and downstream of this reference tube. These functions produce the desired transfer matrix poles.

The resulting matrix is validated by inserting the tube in the intake lines of two four-cylinder engines which are modeled in GT-Power. Pressure and mass flow are registered at the measurement points of the tube from the simulation. The time series data upstream of the tube is treated in the frequency domain and the transfer matrix is used to calculate the corresponding downstream values. Measured values from the native simulation and those calculated using the transfer matrix propagation are then compared.

Finally, the experimental technique for identifying transfer matrices of more complex elements using two versions of the previous tube is presented.

\section{INTRODUCTION}

It has long been realized that the design of the intake and exhaust lines has a large effect on the performance of an internal combustion engine [1]. This explains the growing need for engine simulation tools able to provide fast and accurate results. At the moment, the most popular technique for engine simulation is based on one-dimensional gas dynamics schemes that solve the 1D Euler equations in an iterative manner over a number of pipes and junctions that make up the intake and exhaust systems [2]. The disadvantage of such techniques is that they remain rather time consuming and require considerable computing power. In fact the flows in the induction and exhaust processes are highly compressible, unsteady and depending on engine speed, in herein the difficulty of simulation. This is due to the nature of operation of a reciprocating engine. The second disadvantage or limitation of these codes is the difficulty to correctly model complex geometry and take into account all the different aspects of the flow.

The usage of acoustic theory for internal combustion engine applications was the interest of many authors but it was notably for the treatment of orifice noise and the predictive acoustic modeling in the intake and exhaust lines [3] [4] [5]. 
The linear theory of gas dynamics can be extended to study the impact of wave action and frequency response on the filling and emptying of an internal combustion engine (ICE). The cycling operation of intake and exhaust valves leads to a series of pulses that enters the geometry at one end and causes the trapped air mass to vibrate and reflect at the other end. This is known as the natural frequency of the system whose value can be calculated using acoustic theory and plane wave decomposition, [6] [7]. Desmet [8] employed impedance calculations to study the influence of the intake geometry on the characteristic performance of a diesel engine. Acoustic theory has also been used from a simulation point of view rather than just a tool to describe and study wave action. Harrison et al. [9] used the calculated impedance and volumetric flow rate through the intake valve to obtain time domain pressure data. They concluded that the inertial ram effect was necessary to model especially at high speeds in order to obtain good results. However they employed corrections in the form of complex wave numbers and Mach number [4] to take into account effects of mean flow. This was done by considering a constant air speed through the intake valve when it is opened and a zero mean air speed when it is closed. Thus decoupling acoustic source from response, meaning that the unsteady source causes wave action but the latter cannot be the origin of unsteady air fluctuations [9]. Recently, Chalet et al. [10] proposed a new frequency based approach; it is based on a transfer function [11] linking pressure and mass flow rate excitation. This transfer function is characteristic of a given intake line and it incorporates inertial mass phenomena. Once its parameters were identified on the dynamic flow bench [12] it was coupled to a GT-Power time domain simulation via Simulink. The method exhibited promising results.

However, the transfer function approach as presented in [10][12] depicts certain limitations. The most pressing would be the difficulty to implement such as technique for a turbocharged engine, that would require mounting the entire air intake line on the dynamic flow bench. This is problematic because a turbocharged engine application comes with thermal discontinuities and unknown boundary conditions: charge air cooler and compressor. The solution would be to split the air intake line into separate elements or blocks and thus introducing transfer matrix notions into engine flow simulation. Transfer matrices are nothing new, they are a linearization of the pressure and velocity fluctuations in the frequency domain while assuming a 1-D plane wave action. For this hypothesis to be valid the frequency range must stay below the cutoff frequency of the first diametric mode. This is the case for the frequencies of interest for engine filling even for typical maximum transverse dimensions of intake elements [3].

To et al. [13] derived analytical transfer matrices for simple acoustic elements (tubes and expansion chambers), and also described an experimental transient technique for determining the matrix parameters of more complex elements. Munjal [3] presents an excellent reference for calculation of impedance and transfer matrices of various elements and discontinuities. It is important to note that these transfer matrices are dedicated to relative pressure and acoustic particle velocity fluctuations. The wave action in an internal combustion engine is different from conventional acoustic flows because the relative pressure and mass flow fluctuations take place with a relatively high mean flow which is never constant but unsteady, dependant on engine speed and on the wave action of the geometry itself. Furthermore, a moving medium will make acoustic measurements more difficult and will introduce instabilities particularly to regions with variable cross section. According to Munjal et al. [14], the problems related to a moving medium are accentuated when large gradients of pressure and velocity appear and the presence of a mean flow mainly affects the low frequency range and creates random noise patterns.

In this work, the transfer function model identified on the dynamic flow bench for a $185 \mathrm{~mm}$ tube is extended to a four pole model linking pressure and mass flow rate upstream and downstream of the tube at designated measurements points. A transfer matrix is thus obtained. The tube is placed in a GTPower code of a four cylinder engine, and the corresponding matrix is validated by checking that it is capable of correctly transmitting pressure and mass flow information.

Finally the experimental technique for identifying transfer matrices of a more complex system, such as a CAC, is introduced. The perspectives of such a method and the versatility of such a matrix are explained.

\section{NOMENCLATURE}

$\begin{array}{cc}\mathrm{p}_{\mathrm{absolute}} & \text { Resultant relative static pressure (mbar) } \\ \mathrm{p}_{0} & \text { Initial relative pressure at rest (mbar) } \\ \mathrm{p}_{\text {loss }} & \text { Steady state pressure drop (mbar) } \\ \mathrm{p} & \text { Unsteady pressure fluctuations (mbar) } \\ \mathrm{x} & \text { Abscissa along the tube }(\mathrm{m}) \\ \mathrm{t} & \text { Time (sec) } \\ \mathrm{s} & \text { Laplace variable } \mathrm{s}=\mathrm{jw} \\ \mathrm{p}(\mathrm{x}, \mathrm{t}) & \text { Instantaneous relative pressure }(\mathrm{mbar}) \\ \mathrm{q}_{\mathrm{m}}(\mathrm{x}, \mathrm{t}) & \text { Instantaneous mass flow }(\mathrm{Kg} / \mathrm{h}) \\ \mathrm{u} & \text { Fluid velocity }(\mathrm{m} / \mathrm{s}) \\ \mathrm{X}_{\mathrm{st}} & \text { Steady state loss coefficient }(\mathrm{mbar} . \mathrm{h} / \mathrm{Kg}) \\ \mathrm{qm} & \text { Mass flow excitation profile }(\mathrm{Kg} / \mathrm{h}) \\ \mathrm{qm}_{\mathrm{steady}} & \text { Initial steady mass flow on bench }(\mathrm{Kg} / \mathrm{h}) \\ \mathrm{qm}_{\text {mean }} & \text { Mean flow }(\mathrm{Kg} / \mathrm{h}) \\ \mathrm{P}(\mathrm{jw}) & \text { Pressure in the frequency domain }(\mathrm{mbar})(\mathrm{jw}) \\ \mathrm{Q}_{\mathrm{m}}(\mathrm{jw}) & \text { Excitation in the frequency domain }(\mathrm{Kg} / \mathrm{h})(\mathrm{jw}) \\ \mathrm{a}_{0} & \text { Speed of sound at rest }(\mathrm{m} / \mathrm{s}) \\ \mathrm{w}_{\mathrm{i}} & \text { Angular frequency of the } \mathrm{i}^{\text {th }} \text { mode }(\mathrm{rad} / \mathrm{s})\end{array}$




$\begin{array}{cc}\varepsilon_{\mathrm{i}} & \text { Damping coefficient for the } \mathrm{i}^{\text {th }} \text { mode } \\ \mathrm{a}_{\mathrm{i}} & \text { Weight coefficient of the } \mathrm{i}^{\text {th }} \text { mode } \\ \mathrm{f}_{\mathrm{i}} & \text { Resonating frequency for the } \mathrm{i}^{\text {th }} \text { mode } \\ \mathrm{X}_{\mathrm{in}} & \text { Ram effect parameter (mbar } /(\mathrm{Kg} / \mathrm{h} . \mathrm{rad})) \\ \mathrm{TF} & \text { Pressure transfer function at point } 1 \\ \mathrm{PF}_{2,3} & \text { Pressure transfer functions at point } 2,3 \\ \mathrm{QF}_{2,3} & \text { Mass flow transfer functions at point } 2,3 \\ \mathrm{k}_{\mathrm{i}} & \text { Wave number for the } \mathrm{i}^{\text {th }} \text { mode } \\ \mathrm{L} & \text { Length of the discussed geometry }(\mathrm{m}) \\ \mathrm{Z}_{\mathrm{c}} & \text { Characteristic pipe impedance }\left(\mathrm{m}^{-1} \cdot \mathrm{s}^{-1}\right) \\ \mathrm{A} & \text { Pipe cross section }\left(\mathrm{m}^{2}\right) \\ \mathrm{Q}_{\mathrm{m}_{\text {excitation }}} & \text { "Adequate" excitation for transfer matrix }(\mathrm{Kg} / \mathrm{h}) \\ {[\mathrm{TM}]} & \text { Transfer matrix of the tube } \\ \widehat{\mathrm{P}} & \text { Transfer matrix pressure variable }(\mathrm{mbar}) \\ \widehat{\mathrm{Q}}_{\mathrm{m}} & \text { Transfer matrix mass flow variable }(\mathrm{Kg} / \mathrm{h}) \\ \mathrm{A}, \mathrm{B}, \mathrm{C}, \mathrm{D} & \text { Transfer matrix poles } \\ \mathrm{P}_{[\mathrm{GT}]} & \text { GT-Power relative pressure }(\mathrm{mbar})(\mathrm{jw}) \\ \mathrm{Qm}_{[\mathrm{GT}]} & \text { GT-Power mass flow }(\mathrm{Kg} / \mathrm{h})(\mathrm{jw})\end{array}$

\section{DYNAMIC FLOW BENCH - SIMPLE TUBE}

A $185 \mathrm{~mm}$ tube along with its adaptation part is mounted on the impulse generator of the dynamic flow bench as shown in figure (1). A nominal steady mass flow rate $\mathrm{q}_{\mathrm{m}_{\text {steady }}}$ is aspirated through the geometry and once the flow stabilizes it is abruptly eliminated in $0.5 \mathrm{~ms}$ using a guillotine system. The result is a mechanical nearly impulse excitation of the air column in the tube. Kistler $4005 \mathrm{AA} 2 \mathrm{R}$ pressure transducers are mounted against the wall at designated locations as shown in figure (1). They allow for time series data of pressure to be registered. The absolute pressure inside the tube can be thought of as a linear superposition of three main components:

$$
\mathrm{p}_{\text {absolute }}=\mathrm{p}_{0}+\mathrm{p}_{\text {loss }}+\mathrm{p}
$$

Where $p_{0}$ in equation (1) is the pressure value of the ambient air at rest before any excitation, $p_{\text {loss }}$ is the mean pressure loss which is conventionally expressed as a function of the square of the steady fluid velocity $u$. The pressure drop is due to the initial nominal mean flow $\mathrm{q}_{\mathrm{m}_{\text {steady }}}$ and it can be written as a function of that flow. So for the specific geometry of figure (1) it is possible to express $p_{\text {loss }}$ as:

$$
\mathrm{p}_{\text {loss }}=\mathrm{X}_{\text {st }} \mathrm{qm}_{\text {steady }}{ }^{2}
$$

$\mathrm{X}_{\mathrm{st}}$ can be measured, it has a value of $\mathrm{X}_{\mathrm{st}}=1.155 \times$ $10^{-3}\left(\mathrm{mbar} / \mathrm{Kg} / \mathrm{h}^{2}\right)$. Finally the term $\mathrm{p}$ in equation (1) refers to the relative pressure fluctuation due to wave action inside the pipe. It is given in the frequency domain $\mathrm{P}(\mathrm{jw})$ by equation (3)

$$
P(j w)=T F \times Q_{m}(j w)
$$

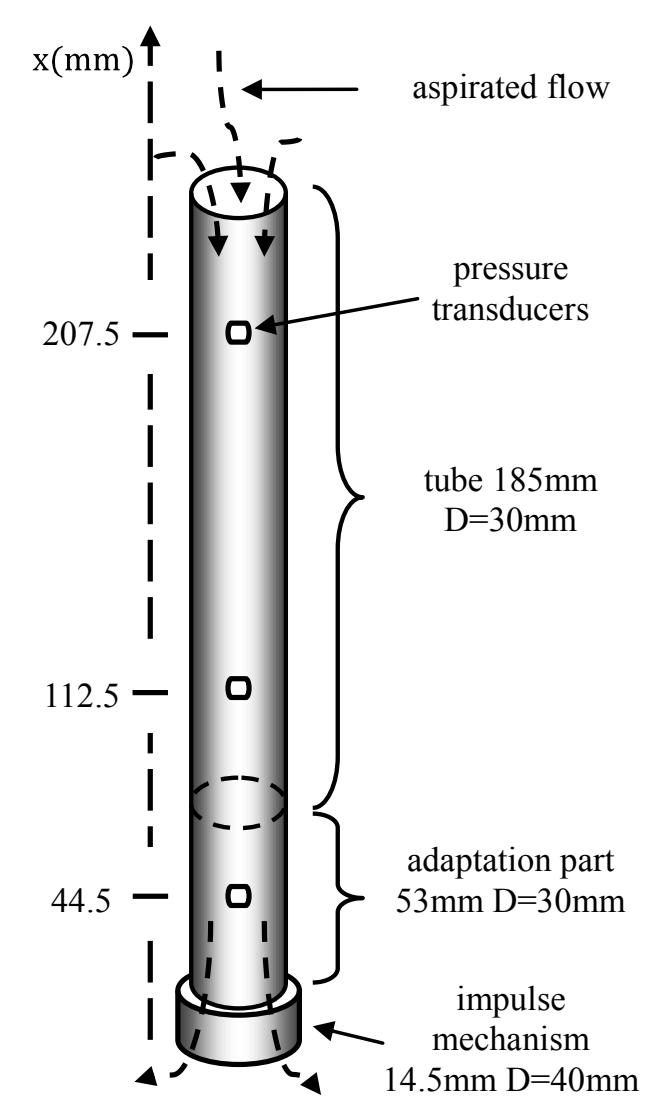

FIGURE 1 - SCHEMATIC OF THE ENTIRE GEOMETRY MOUNTED ON THE FLOW BENCH

Where TF is the corresponding transfer function and depends on the geometry and $\mathrm{Q}_{\mathrm{m}}$ is the mass flow rate excitation that initiated the wave action.

The transfer function $\mathrm{TF}$ at point 1 which is the closest practical point to our excitation is written as follows:

$$
\mathrm{TF}=\sum_{\mathrm{i}=1}^{\mathrm{n}} \frac{\mathrm{a}_{\mathrm{i}} \mathrm{X}_{\mathrm{in}} \mathrm{s}}{\left(\frac{\mathrm{s}}{\mathrm{w}_{\mathrm{i}}}\right)^{2}+\frac{2 \varepsilon_{\mathrm{i}}}{\mathrm{w}_{\mathrm{i}}} \mathrm{s}+1}
$$

The transfer function of equation (4) is a modal decomposition [15] of the pressure response. In theory, there are an infinite number of resonant frequencies that are excited by the impulse mass flow. However in practice we only identify a limited number, the energy associated to higher modes become increasingly small when compared to the fundamental frequency [16].

The transfer function is measured from experiments on the bench. A number of impulses are carried out for a given geometry and the pressure responses are compared each time in order to validate linearity between the tests. Following the registration of time series data of pressure and a specific 
frequency treatment, the complex value of the sampled transfer function is calculated. Equation (4) attempts to model the transfer function using a second order Laplace function for each resonance.

The first parameter of the transfer function $\mathrm{TF}$ is the angular frequency $w_{i}=2 \pi f_{i}$ where $f_{i}$ is the frequency of the $i^{\text {th }}$ mode. It is given directly from measurements by the characteristic frequencies of the peaks of the modulus of the measured TF, otherwise known as the Bode diagram given by figure (2).

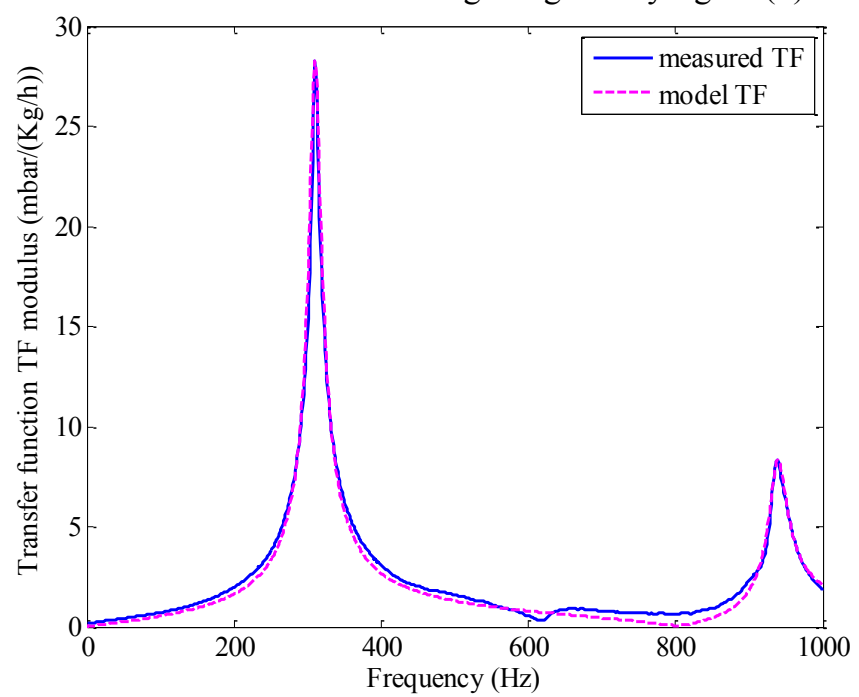

FIGURE 2 - MEASURED AND MODELED TF MODULUS OF PRESSURE FLUCTUATIONS AT POINT 1.

$\mathrm{X}_{\mathrm{in}}$ is known as the inertial ram effect parameter, it is proportional to the amplitudes of the peaks and is a global energy parameter independent of each mode. The damping coefficients $\varepsilon_{\mathrm{i}}$ are given in percentage; they are calculated also from measurements and model the dissipation and losses in the unsteady pressure waves. Finally, in order to limit the model to a certain number of resonance frequencies, the frequency window $0-1000 \mathrm{~Hz}$ is only modeled. This is well sufficient for an engine filling and emptying application. Therefore, only " $\mathrm{n}$ " resonant frequencies are identified, the energy associated to each mode is calculated via weight coefficients $a_{i}$ that must validate $\sum_{\mathrm{i}=1}^{\mathrm{n}} \mathrm{a}_{\mathrm{i}}=1$ in the frequency range in question. For the geometry of figure (2), two frequencies were identified. The corresponding parameters are given by table 1 .

TABLE 1 - IDENTIFIED PARAMETERS OF TRANSFER FUNCTION TF Transfer Function TF

\begin{tabular}{c|c|c}
\hline & $\mathrm{i}=1$ & $\mathrm{i}=2$ \\
\hline $\mathrm{f}(\mathrm{Hz})$ & 310 & 938 \\
\hline$\varepsilon(\%)$ & 2.55 & 1.24 \\
\hline $\mathrm{a}(\%)$ & 95.5 & 5.5 \\
\hline \multicolumn{2}{c|}{$\mathrm{X}_{\text {in }}(\mathrm{mbar} /(\mathrm{Kg} / \mathrm{h} . \mathrm{rad}))$} & $7.382 \mathrm{e} 4$ \\
\hline
\end{tabular}

\section{PRESSURE PROPAGATION}

When the tube is subjected to the impulse excitation, the air column inside the tube vibrates with its proper frequencies. This system of fluctuations is in fact the superposition of elementary sinusoidal vibrations whose corresponding frequencies are multiple of each other. These vibrations are characterized with maxima and minima of pressure and velocity that occupy fixed positions along the length of the tube. The resonant frequencies depend on the length and termination of the tube. After excitation a distribution of quarter wave length is established inside the tube.

The theoretical pressure distribution of the air column along the axis of the geometry after choosing the closed end as a reference section for a resonant frequency " $i$ "at any given instant " $\mathrm{t}$ "and abscissa " $\mathrm{x}$ "can be written as:

$$
\mathrm{p}_{\mathrm{i}}(\mathrm{x}, \mathrm{t})=\mathrm{p}_{\mathrm{i}}(0, \mathrm{t}) \times \cos \left(\mathrm{k}_{\mathrm{i}} \mathrm{x}\right)
$$

Where $\mathrm{k}_{\mathrm{i}}$ in equation (5) is the wave number given by:

$$
\mathrm{k}_{\mathrm{i}}=\frac{\mathrm{w}_{\mathrm{i}}}{\mathrm{a}_{0}}
$$

$a_{0}$ is the local speed of sound supposed to be constant for an ambient temperature of $293 \mathrm{~K}$. A real wave number instead of a complex one like usually employed in acoustics [3][4] is chosen. This is because the dissipative effects are not meant to be incorporated in this term. It is rather a term for propagation and phase shift, losses along propagation will be introduced in specific damping coefficients for each resonance at any abscissa. Equation (5) can be written in the frequency domain after normalizing with $Q_{m}$ for pressures at points 2 and 3 of figure (1) as follows:

$$
\begin{aligned}
& \frac{P_{2}}{Q m}=\sum_{i=1}^{n} \frac{a_{i} X_{i n} s}{\left(\frac{s}{w_{i}}\right)^{2}+\frac{2 \xi_{i} s}{w_{i}}+1} \times \frac{\cos \left(k_{i} x_{2}\right)}{\cos \left(k_{i} x_{1}\right)} \\
& \frac{P_{3}}{Q m}=\sum_{i=1}^{n} \frac{a_{i} X_{i n} s}{\left(\frac{s}{w_{i}}\right)^{2}+\frac{2 Y_{i} s}{w_{i}}+1} \times \frac{\cos \left(k_{i} x_{3}\right)}{\cos \left(k_{i} x_{1}\right)}
\end{aligned}
$$

Equations (7) and (8) are the transfer functions of pressure at points 2 and 3 respectively:

And

$$
\mathrm{PF}_{2}=\frac{\mathrm{P}_{2}}{\mathrm{Q}_{\mathrm{m}}}
$$

$$
\mathrm{PF}_{3}=\frac{\mathrm{P}_{3}}{\mathrm{Q}_{\mathrm{m}}}
$$

The resonant frequencies, ram effect parameter and weight coefficients are independent of propagation. Whereas the damping parameters of each resonance will change with propagation, they integrate losses due to propagation as stated before. 
TABLE 2 - DAMPING COEFFICIENTS WITH PROPAGATION

$$
\mathrm{PF}_{2} \quad \mathrm{PF}_{3}
$$

\begin{tabular}{cc}
\hline$\xi_{1}=2.6 \%$ & $\Upsilon_{1}=3 \%$ \\
\hline$\xi_{2}=0.6 \%$ & $\Upsilon_{1}=1 \%$ \\
\hline
\end{tabular}

The damping coefficients for the transfer functions $\mathrm{PF}_{2}$ and $\mathrm{PF}_{3}$ are calculated after registering the pressure response at abscissa 2 and 3 and checking peak modulus. They are given in table 2.

Figure (3) compares measured and modeled modulus of $\mathrm{PF}_{3}$. Two frequencies were modeled: the main resonant frequency at $310 \mathrm{~Hz}$ and its first harmonic at $938 \mathrm{~Hz}$. The middle peak at $622 \mathrm{~Hz}$ corresponds to half wave resonance. It is not taken into consideration in this paper. Its effects are attributed for the time being to a non-linearity at the opened end. This non-linearity is thought to be caused by the large pressure amplitudes inside the pipe that are reflected at the opened end. For this reason, this frequency was not integrated into the model and by inspecting figure (4) it is clear that this frequency has little influence on the global signal, which is logical since the resonant energy is primary dedicated to quarter wave resonance.

The transfer functions $\mathrm{PF}_{2}$ and $\mathrm{PF}_{3}$ were calculated because they allow access to the linear information. In fact, the impulse excitation on the dynamic flow bench gives the most elementary response that can be measured. This dynamic response is accessed via the transfer functions. Later this concept of elementary response will be used to excite the transfer functions with a "suitable" mass flow. This will be one for transfer matrix computations.

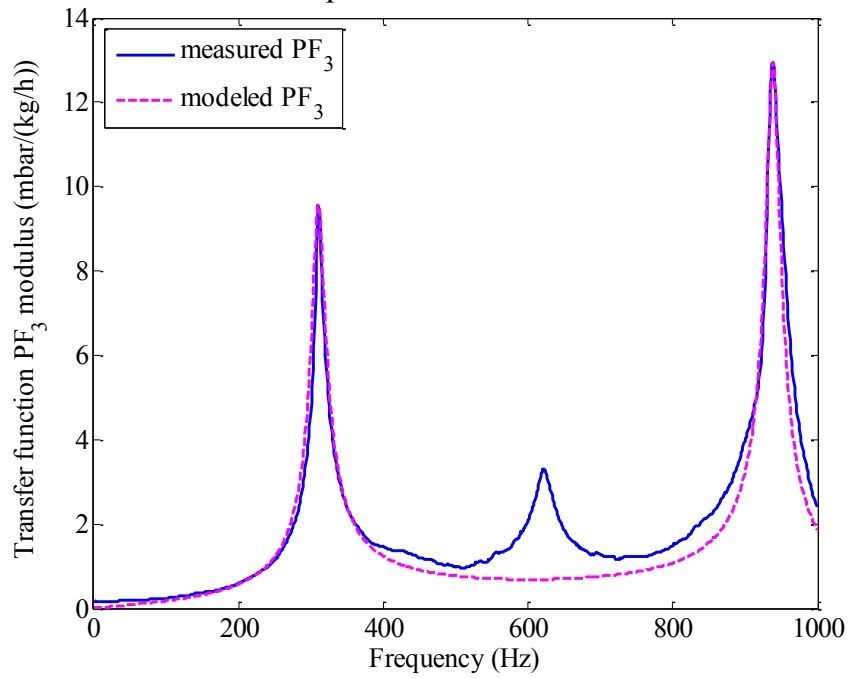

FIGURE 3 - MEASURED AND MODELED $\mathrm{PF}_{3}$ MODULUS OF PRESSURE FLUCTUATIONS AT POINT 3.
The idea behind exciting this "adequate" mass flow excitation is to obtain reliable pressure data which can be used in FFT calculations.

Figure (4) compares time domain pressure response at point 2. This is obtained by exciting $\mathrm{PF}_{2}$ with the same transient impulse profile as the one used on the experimental bench. An inverse Laplace is then carried out for all the resonant frequencies.

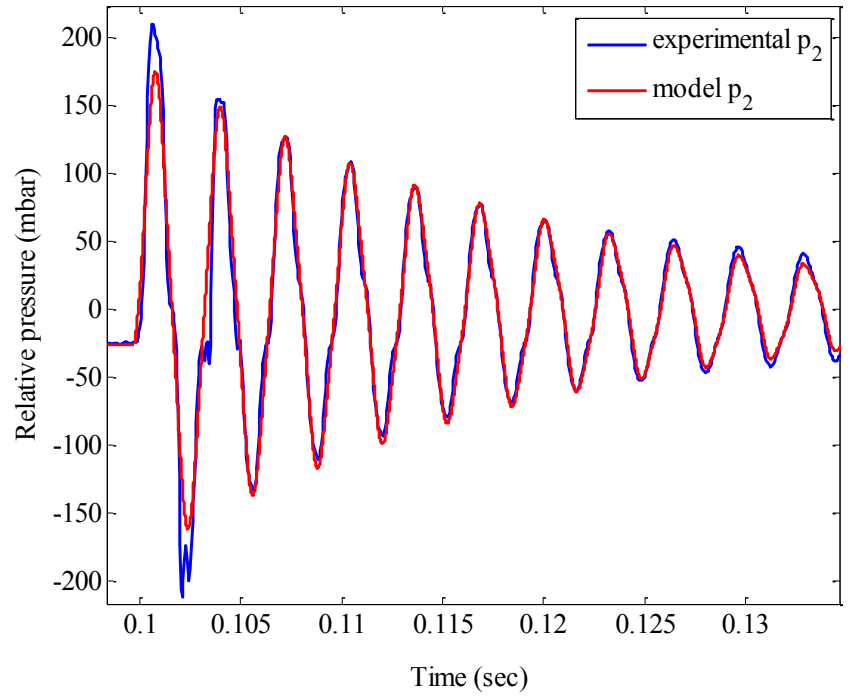

FIGURE 4 - MEASURED AND MODELED PRESSURE RESPONSE AT POINT 2.

Good agreement is obtained, and functions $\mathrm{PF}_{2}$ and $\mathrm{PF}_{3}$ are capable of faithfully reproducing the reality of the dynamic flow bench.

\section{MASS FLOW PROPAGATION}

The linearized continuity and momentum equations [16] can be written for a uniform tube of section $A$ in terms of fluctuating pressure $\mathrm{p}(\mathrm{x}, \mathrm{t})$ and mass flow $\mathrm{q}_{\mathrm{m}}(\mathrm{x}, \mathrm{t})$

$$
\frac{\partial p(x, t)}{\partial t}+z_{c} a_{0} \frac{\partial q_{m}(x, t)}{\partial x}=0
$$

And

$$
\frac{1}{\mathrm{~A}} \frac{\partial \mathrm{q}_{\mathrm{m}}(\mathrm{x}, \mathrm{t})}{\partial \mathrm{t}}+\frac{\partial \mathrm{p}(\mathrm{x}, \mathrm{t})}{\partial \mathrm{x}}=0
$$

Where $\mathrm{Z}_{\mathrm{c}}$ is the pipe characteristic impedance: $Z_{c}=a_{0} / A$.

Writing equations (9) and (10) in the Laplace domain and eliminating the variable $s=j w$, equation (11) is obtained

$$
\mathrm{Z}_{\mathrm{c}}^{2} \mathrm{Q}_{\mathrm{m}}(\mathrm{x}, \mathrm{s}) \frac{\partial \mathrm{Q}_{\mathrm{m}}(\mathrm{x}, \mathrm{s})}{\partial \mathrm{x}}=\mathrm{P}(\mathrm{x}, \mathrm{s}) \frac{\partial \mathrm{P}(\mathrm{x}, \mathrm{s})}{\partial \mathrm{x}}
$$

Knowing pressure distributions at points 2 and 3 from the transfer functions given by equations (7) and (8) it is then possible to find the mass flow variations at these points both in the frequency and time domains by solving equation (11). Because the values of the damping parameters are not known as 
a function of $\mathrm{x}$ but are computed from each measurement point, approximate values of the mass flow variations are to be obtained. Consequently two additional transfer functions are defined as

and

$$
\mathrm{QF}_{2}=\frac{\mathrm{Q}_{\mathrm{m}_{2}}}{\mathrm{Q}_{\mathrm{m}}}
$$

$$
\mathrm{QF}_{3}=\frac{\mathrm{Q}_{\mathrm{m}_{3}}}{\mathrm{Q}_{\mathrm{m}}}
$$

$\mathrm{QF}_{2}$ and $\mathrm{QF}_{3}$ have the same structure as the pressure functions. The corresponding parameters were calculated.

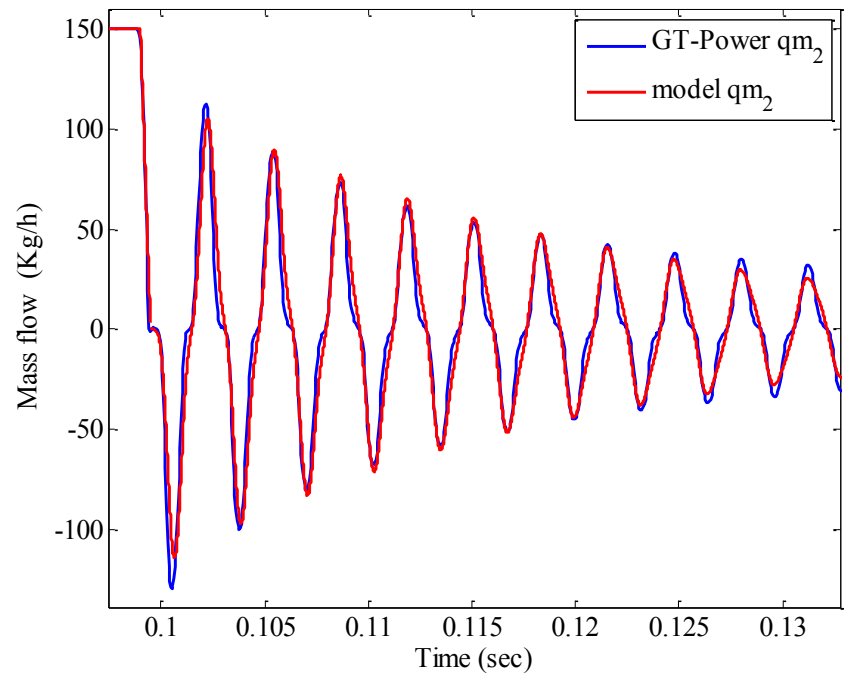

FIGURE 5 - GT-POWER AND MODELED MASS FLOW RESPONSE AT POINT 2.

In order to validate the new model, a GT-Power model of the dynamic flow bench was constructed with the same geometry as figure (1). The 1D model was calibrated in order to give good results in terms of pressure variations at all the measurement points. Once the GT-Power model gave good results for pressure, it should also give correct values for the mass flow. Figure (5) compares the mass flow rate from the GT-Power model against that obtained with the transfer function model $\mathrm{QF}_{2}$. Quarter wave length resonance is verified as being the preponderant system for the stationary wave action. Good agreement is shown and the linear approximation of equation (11) is sufficient for the dynamic flow bench.

\section{TRANSFER MATRIX IDENTIFICATION}

Considering the geometry of figure (1), the idea behind a transfer matrix is that pressure and mass flow fluctuations at point 3 are linearly dependent on their counterparts at point 2 . This linear relationship exists in the frequency domain and it depends on the geometry and conditions that exists between the two points. This can be written as:

$$
\left(\begin{array}{c}
\widehat{\mathrm{P}}_{3} \\
\widehat{\mathrm{Q}}_{3}
\end{array}\right)=[\mathrm{TM}] \times\left(\begin{array}{c}
\widehat{\mathrm{P}}_{2} \\
\widehat{\mathrm{Q}}_{2}
\end{array}\right)
$$

The pressure and mass flow rate in equation (12) are information in the frequency domain as follows:

$$
\begin{gathered}
\hat{\mathrm{P}}_{\mathrm{x}}=\left\{\mathrm{p}_{\text {loss }}(\mathrm{x}, \mathrm{t})+\mathrm{p}(\mathrm{x}, \mathrm{t})\right\}_{\mathrm{jw}} \\
\widehat{\mathrm{Q}}_{\mathrm{m}_{\mathrm{x}}}=\left\{\mathrm{q}_{\mathrm{m}_{\text {mean }}}(\mathrm{x}, \mathrm{t})+\mathrm{q}_{\mathrm{m}}(\mathrm{x}, \mathrm{t})\right\}_{\mathrm{jw}}
\end{gathered}
$$

Where $\{\mathrm{p}(\mathrm{x}, \mathrm{t})\}_{\mathrm{jw}}$ and $\left\{\mathrm{q}_{\mathrm{m}}(\mathrm{x}, \mathrm{t})\right\}_{\mathrm{jw}}$ at abscissa $" \mathrm{x} "$ are obtained by exciting the corresponding transfer functions $\mathrm{PF}_{\mathrm{x}}$ and $\mathrm{QF}_{\mathrm{x}}$ with an "adequate" mass flow rate:

$$
\left\{\begin{array}{c}
\mathrm{p}(\mathrm{x}, \mathrm{t}) \\
\mathrm{q}_{\mathrm{m}}(\mathrm{x}, \mathrm{t})
\end{array}\right\}_{j w}=\left[\begin{array}{c}
\mathrm{PF}_{\mathrm{x}} \\
\mathrm{QF}_{\mathrm{x}}
\end{array}\right] \times\left[\mathrm{Q}_{\mathrm{m}_{\text {excitation }}}\right]
$$

Thus the variables at points 2 and 3 of equation (12) were computed using the transfer functions for pressure and mass flow calculated earlier. These functions were excited artificially with $\mathrm{Q}_{\mathrm{m}_{\text {excitation }}}$ as a mass flow excitation thus insuring the required energy level of each resonance mode in the frequency range of the engine were the tube will be placed later on.

Writing the transfer matrix [TM] as

$$
[\mathrm{TM}]=\left[\begin{array}{ll}
\mathrm{A} & \mathrm{B} \\
\mathrm{C} & \mathrm{D}
\end{array}\right]
$$

And introducing reciprocal and symmetric properties [17] for the piping between sensor 2 and 3 one can write

$$
\mathrm{A}=\mathrm{D} \text { and } \mathrm{A} \times \mathrm{D}-\mathrm{B} \times \mathrm{C}=1
$$

The properties of equation (16) were verified by inverting the $185 \mathrm{~mm}$ tube of figure (1) and repeating the experiment with the same initial excitation $\mathrm{qm}_{\text {steady }}$.

\section{SIMULATION IN GT-POWER}

In order to validate the transfer matrix [TM] of the $185 \mathrm{~mm}$ tube, the latter was modeled in GT-Power and placed in the intake line of two four cylinder engines. The tube was equipped with mass flow and pressure sensors at the same locations shown in figure (1). The virtual sensors registered time series data during the engine's simulation run. The validation of the transfer matrix is done in the following manner: time series data of pressure and mass flow rate $\mathrm{p}_{2}$ and $\mathrm{qm}_{2}$ at point 2 were measured during the run. Then a FFT treatment is used to get information in the frequency domain: $\mathrm{P}_{2}$ and $\mathrm{Qm}_{2}$; next the frequency vectors were convoluted by the transfer matrix [TM]. Thus values of pressure and mass flow rate at point 3 are calculated from the transfer matrix [TM] and obtained in the frequency domain: $\mathrm{P}_{3}[\mathrm{TM}]$ and $\mathrm{Qm}_{3}[\mathrm{TM}]$. An Inverse Fourier Transform analysis is performed on the previous signals and the time domain response is calculated: $\mathrm{p}_{3}$ [TM] and $\mathrm{qm}_{3}$ [TM]. Finally $p_{3}[\mathrm{TM}]$ and $\mathrm{qm}_{3}[\mathrm{TM}]$ are compared against $\mathrm{p}_{3}$ and $\mathrm{qm}_{3}$ measured with the GT-Power sensors. The engine models existed a priori in GT-Power, and were calibrated and compared to experimental measurements. Equations (17) and (18) summarize the procedure just described: 


$$
\begin{gathered}
\mathrm{P}_{3_{[\mathrm{TM}]}}=\mathrm{A} \times \mathrm{P}_{2_{[\mathrm{GT}]}}+\mathrm{B} \times \mathrm{Qm}_{2_{[\mathrm{GT}]}} \\
\mathrm{Qm}_{3_{[\mathrm{TM}]}}=\mathrm{C} \times \mathrm{P}_{2_{[\mathrm{GT}]}}+\mathrm{D} \times \mathrm{Qm}_{2_{[\mathrm{GT}]}}
\end{gathered}
$$

The first engine is a four cylinder 1.61 petrol engine simulated at 3000 RPM. A tubular piece of one of the main runners was replaced in GT-Power with the $185 \mathrm{~mm}$ tube as shown in figure (6).

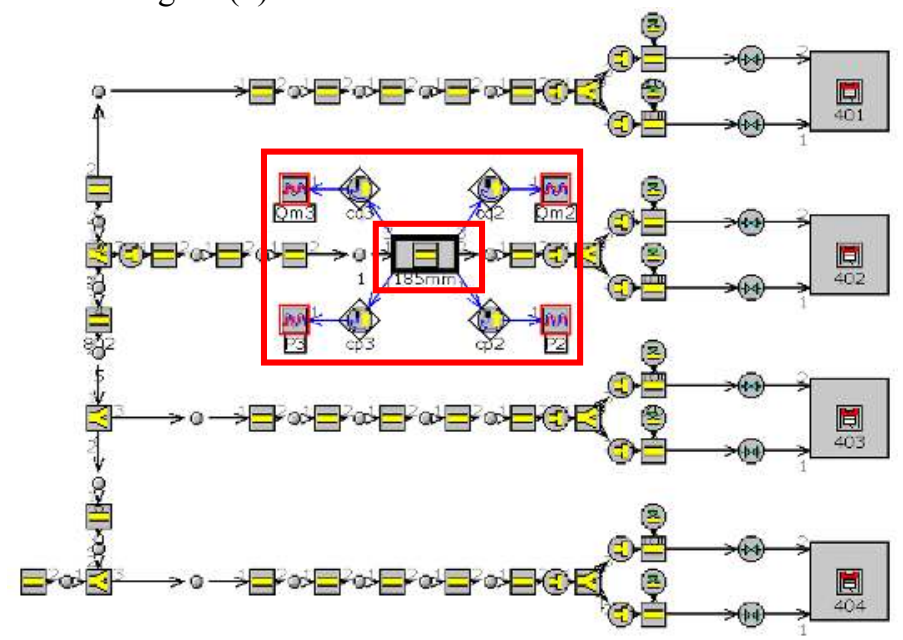

FIGURE 6 - SNAPSHOT IN GT-POWER OF THE 185MM TUBE PLACED IN THE PRIMARY RUNNER OF THE PETROL ENGINE

The idea behind these simulations is to verify that the transfer matrix of the tube is capable of correctly transmitting the information from point 2 to point 3 for different kinds of excitations, i.e. different positions in the intake line, different engine configurations and different speeds. This results in different frequency ranges for each application and different mean flows. The objective is to have a matrix that gives good results without having to calibrate or know in advance the instantaneous Mach number profile.

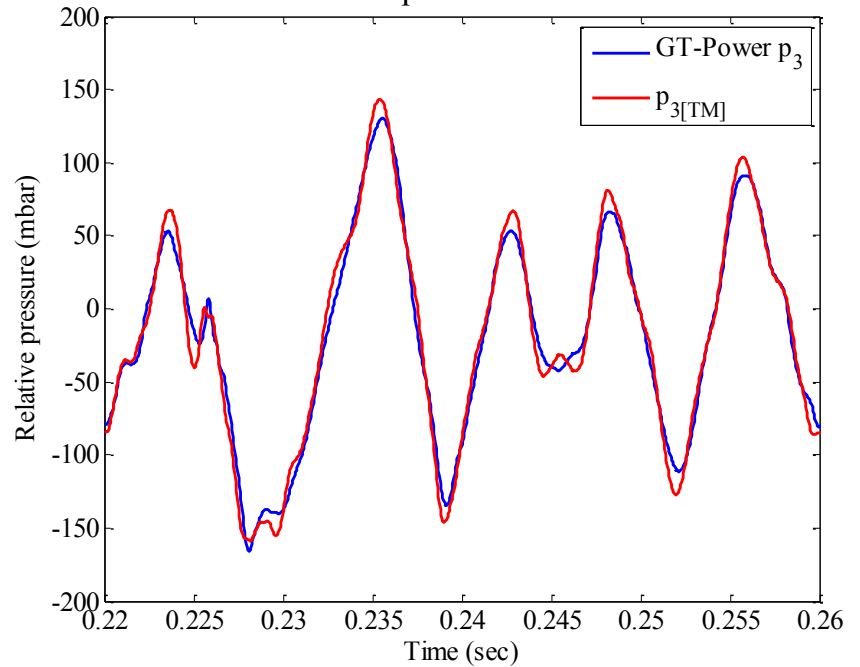

FIGURE 7 - PRESSURE IN THE PRIMARY RUNER MEASURED FROM GTPOWER AND CALCULATED USING EQUATION (17)
Figure (7) compares pressure waves at point 3 obtained directly from GT-Power and the ones computed with the transfer matrix using the registered pressure and mass flow at point 2 . In terms of mass flow response, figure (8) compares the results. The pressure is correctly transmitted with the transfer matrix. More important differences are noticed for the mass flow response where the damping is under estimated. These differences may be attributed to the approximation of equation (11) that models incorrectly the damping. But also, and more importantly, these discrepancies manifest according to engine speed, meaning they depend on the frequency of excitation. This means that is necessary to incorporate more information in the transfer matrix poles for these frequencies.

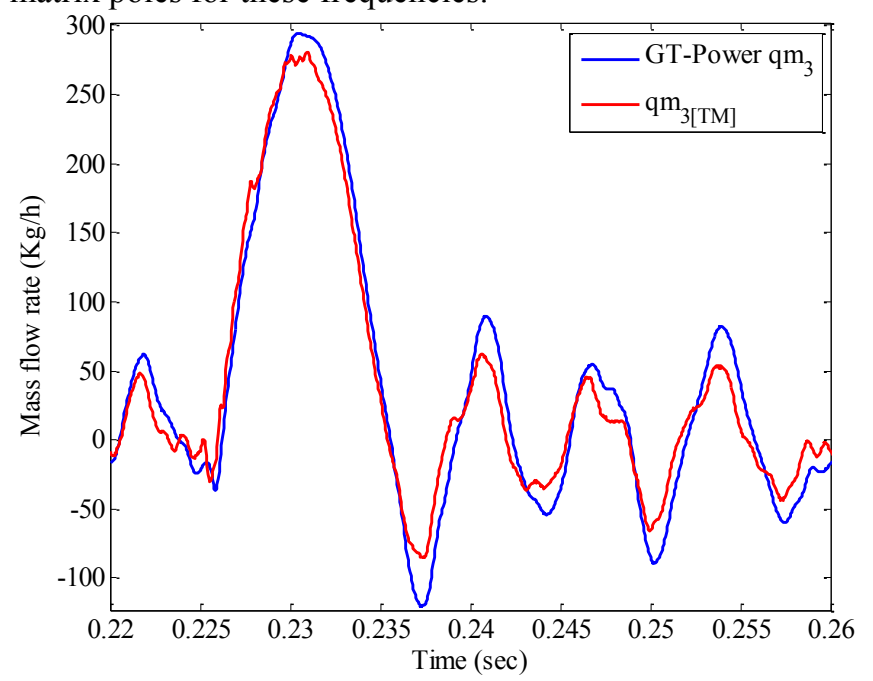

FIGURE 8 - MASS FLOW IN THE PRIMARY RUNNER MEASURED FROM GT-POWER AND CALCULATED USING EQUATION (18)

The second engine is a turbocharged diesel engine. This time the $185 \mathrm{~mm}$ tube was placed downstream of the charge air cooler CAC. The engine speed was set to 4250 RPM. Figures (9) and (10) give the results for pressure and mass flow rate respectively.

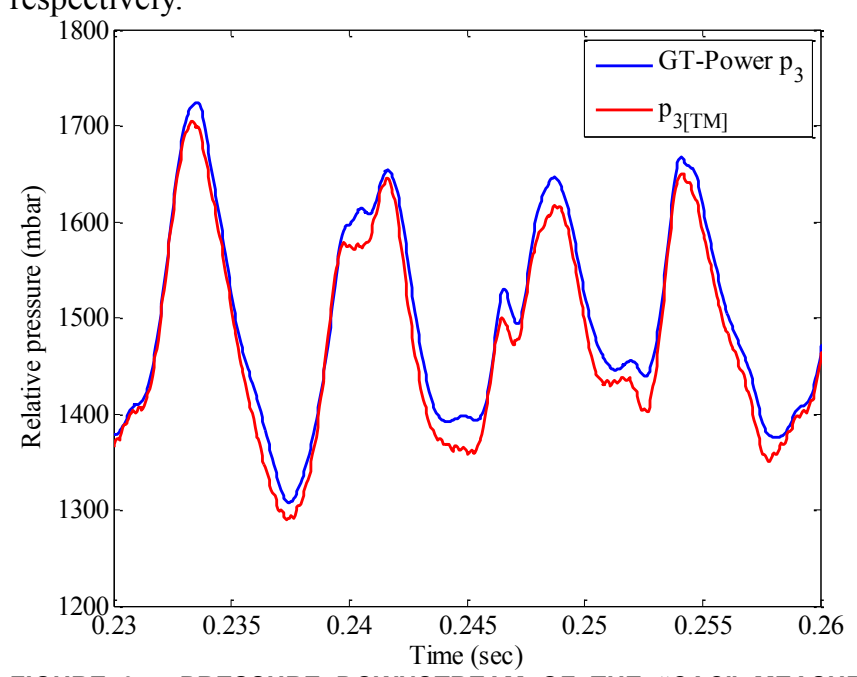

FIGURE 9 - PRESSURE DOWNSTREAM OF THE "CAC" MEASURED FROM GT-POWER AND CALCULATED USING EQUATION (17) 
Using the same procedure, pressure and mass flow were computed at point 3.Overall agreement is good, but differences exist especially for the pressure response in this case. This confirms the necessity to make the matrix more robust, i.e. have a larger number of peaks in the frequency spectrum on the dynamic flow bench, in order to better characterize the matrix.

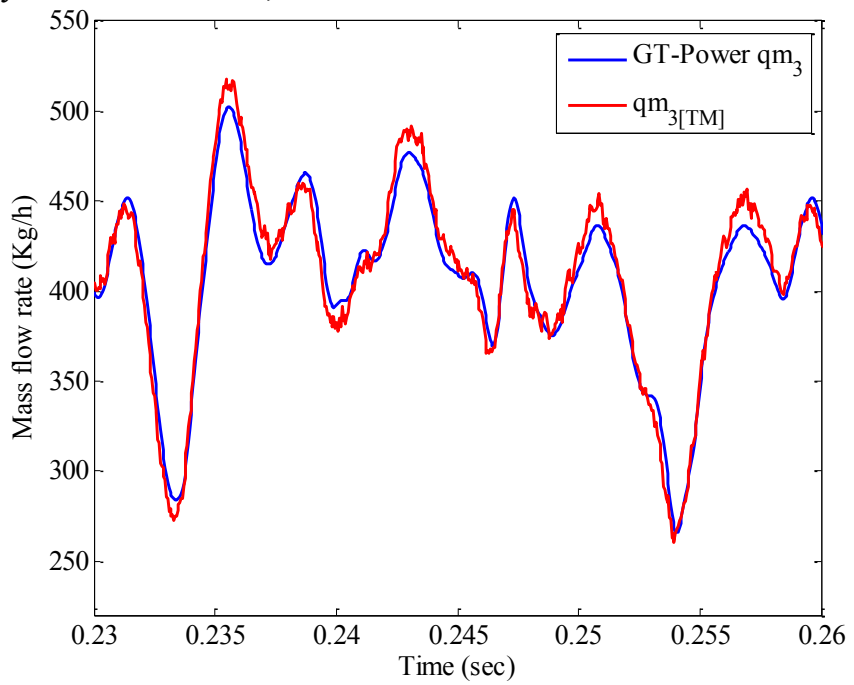

FIGURE 10 - MASS FLOW DOWNSTREAM OF THE "CAC" MEASURED FROM GT-POWER AND CALCULATED USING EQUATION (18)

\section{CONCLUSIONS AND FUTURE WORK}

The transfer function technique on the dynamic flow bench was used for a simple element to characterize a transfer matrix across the tube written in terms of pressure and mass flow rate. This was done by measuring the dynamic pressure response experimentally and calculating an approximate mass flow using a known impedance charge: the quarter wave resonator. This allows the computation of four transfer functions, that, when excited correctly define the transfer matrix. GT-Power simulation code was used for validation by placing the tube in the intake line of two engines. The transition from the frequency domain to the time domain and back is necessary when the future aim is engine simulation. Good results were obtained, however differences in mass flow in the main runner when the intake valve closes, suggests an incomplete modeling of the damping when estimating the mass flow on the bench. On the other hand, some differences are noticed for pressure variations when the tube is placed downstream of a CAC. This may be explained by the fact that the matrix was identified at an ambient temperature different than the one present downstream of the CAC. Further investigations are necessary in order to determine temperature influence on wave action and linearity in the frequency domain. It is important to note however, that the computed transfer matrix can be employed in any mean flow conditions and for large gradients of pressure without having to calibrate the matrix at each time and without having to know the instantaneous Mach number profile a priori. Finally, it is clear that the matrix would give the best and most accurate results for excitations that are within the frequency band of the initial response on the bench. These excitation frequencies depend on the geometry (resonance modes) on the entire intake line and on engine speed. It is necessary to evolve the transfer matrix by incorporating more modeled frequencies.

Future work will focus on modeling more frequencies for the same tube, thus obtaining a more robust transfer matrix. The objective is to make it precise enough for any configuration and engine speed. Once the transfer matrix for the tube is "optimized", it is possible to use linear decomposition techniques to find the transfer matrix of a more complex element. In the case of a turbocharged engine, the CAC present a major thermal discontinuity. It will be placed between two identical versions of the previous tube and the entire configuration will be mounted on the bench to measure the dynamic response following an impulse excitation. The transfer matrix of the CAC is then identified. Another aspect is to understand the effect of such a thermal discontinuity on the propagation of the waves. The same configuration as before will be repeated but this time including heat transfer across the CAC. The characterized CAC with heat transfer will help the better evaluation of the influence of a temperature discontinuity on wave action in an ICE.

\section{REFERENCES}

1. BROOME D. - "Induction Ram - Part 2: Inertial aspect of induction ram". Automobile Engineer, p. 180-184, 1969.

2. WINTERBONE D.E., PEARSON R.J. - "Theory of Engine Manifold Design: Wave Action Methods for IC Engines". Professional Engineering Publishing, 2000.

3. MUNJAL M. L. - "Acoustics of ducts and mufflers with application to exhaust and ventilation system design". John Wiley \& Sons, 1987.

4. DAVIES P.O.A.L. - "Practical flow duct acoustic". Vol. 124(1), pp. 91-115, 1988.

5. DAVIES P.O.A.L, HARRISON M.F. - "Predictive Acoustic modeling Applied to the Control of Intake/Exhaust Noise of Internal Combustion Engines". Journal Of Sound and Vibration, Vol. 202(2), pp. 249-274, 1997.

6. OHATA A., ISHIDA Y. - "Dynamic Inlet Pressure and Volumetric Efficiency of Four Cycle Cylinder Engine". Society of Automotive Engineers, n. 820407. 1983.

7. MATSUMOTO I., OHATA A. - "Variable induction systems to improve volumetric efficiency at low and/or medium engine speeds". SAE, p. 1511-1521, 1986. ISSN 860100 .

8. DESMET B. -"Contribution à l'etude de l'influence du circuit d'aspiration sur le remplissage d'un moteur diesel". $\mathrm{PhD}$ thesis, Université des Sciences et Techniques de Lille, 1977. 
9. HARRISON M.F., DUNKLEY A. - "The acoustics of racing engine intake systems". Journal of Sound and Vibration, Vol. 271(3), p. 959-984, DOI: 10.1016/S0022460X(03)00773-9, 2004.

10. CHALET D., MAHE A., HETET J.F., MIGAUD - "A new modeling approach of pressure waves at the inlet of internal combustion engines". Journal of Thermal Science. Vol. 20(2), pp. 181-188, DOI: 10.1007/s11630-011-0455-8, 2011.

11. FONTANA P., BERNHARD H. - "A new evaluation method for the thermodynamic behavior of air intake systems". SAE, n. 2005-01-1136, 2005.

12. CHALET D., MAHE A., MIGAUD J., HETET J.F. - “A frequency modeling of the pressure waves in the inlet manifold of internal combustion engine". Applied Energy, Vol. $88(9), \quad$ pp.2988-2994, DOI: 10.1016/j.apenergy.2011.03.036, 2011

13. TO C.W.S, DOIGE A.G. - "A transient testing technique for the determination of martrix parameters of acoustic systems, I : Theory and principles". Journal of Sound and Vibration, Vol. 62 (2), p. 207-222, 1979.

14. MUNJAL M.L., DOIGE A.G. - "Theory of a Two SourceLocation Method for Direct Experimental Evaluation of the Four-Pole Parameters of an Aeroacoustic Element". Journal Of Sound And Vibration, pp. 323-333, Vol 141(2), 1990.

15. BRUNEAU M. - "Manuel d'acoustique fondamentale", Paris: Hermes, 1998.

16. BOREL M. - "Les phénomènes d'ondes dans les moteurs". Publications de l'IFP, Editions TECHNIP, 2000.

17. MUNJAL M.L., DOIGE A.G. - "Symmetry of OneDimensional Dynamical Systems in Terms Of Transfer Matrix Parameters". Journal Of Sound And Vibration, Academic Press Limited, Vol. 163(3), pp. 467- 475, 1990.

\section{ACKNOWLEDGMENTS}

The author would like to thank the Internal Combustion Engine team at Ecole Centrale de Nantes and the Engine and Acoustic departments in the advanced development at Mann + Hummel France. The authors also thank OSEO Innovation and the Région des Pays de la Loire for their financial contributions in the research program Ocsygene6.

\section{CONTACT INFORMATION}

Haitham MEZHER

Mechanical Engineer, PhD Student

E-mail: haitham.mezher@mann-hummel.com

E-mail: haitham.mezher@ec-nantes.fr 